\title{
CONTRIBUCIÓn al CONOCIMIENTO De PEPEROMIA (PIPERACEAE): FRUTO Y SEMILLA
}

\author{
Marco A. Martínez-Colín'í, E. Mark Engleman y Stephen D. Koch \\ Colegio de Postgraduados, Montecillo, Estado de México, C.P. 56230, México. \\ 'Autor para la correspondencia; correo-e: mmarco@colpos.mx
}

\begin{abstract}
Resumen: Peperomia Ruiz et Pavón comprende un número indeterminado de especies que se distribuyen en las regiones tropicales y subtropicales de ambos hemisferios. Uno de los motivos que atrae el interés hacia este género es la dificultad para determinar sus especies. En este trabajo se muestran las características microscópicas del fruto y la semilla de 17 especies mexicanas de Peperomia, distribuidas en seis subgéneros (Acrocarpidium, Micropiper, Ogmocarpidium, Rhyncophorum, Sphaerocarpidium y Tildenia). Las especies se distinguen por los siguientes caracteres del fruto: (a) la ubicación y la inserción del fruto en el raquis, (b) la forma del ovario, (c) la curvatura del fruto, (d) la composición celular del exocarpio y del endocarpio, (e) la forma del estilo, (f) la posición del estigma, (g) la presencia de cristales en el pericarpio, y (h) la ornamentación de la cutícula epidérmica. Se definen caracteres taxonómicos nuevos y se aclaran términos relacionados con la inserción y la apariencia externa del fruto que se utilizan comúnmente para describir el fruto de Peperomia. Las 17 especies presentan un perispermo amiláceo, un endospermo escaso y un embrión poco desarrollado. Se sugiere el estudio de un mayor número de especies para identificar posibles caracteres o estados de carácter adicionales.
\end{abstract}

Palabras clave: anatomía, estigma, estilo, morfología, pericarpio, pseudocúpula.

\begin{abstract}
Peperomia Ruiz et Pavón comprises an indetermined number of species distributed in tropical and subtropical regions of both hemispheres. One reason for interest in this genus is the difficulty of determining its species. Microscopic features were studied for fruit and seed of 17 Mexican Peperomia species representing six subgenera (Acrocarpidium, Micropiper, Ogmocarpidium, Rhyncophorum, Sphaerocarpidium, and Tildenia). Results show that all 17 materials can be distinguished by fruit characters. The differences among fruits are: (a) location and insertion of fruit on rachis, (b) ovary form, (c) curvature, (d) celular composition in exocarp and endocarp, (e) style form, (f) stigma position, (g) presence of crystals in the pericarp, and (h) dermal cuticle ornamentation. New taxonomic characters are reported, and common terms concerning the insertion and appearance of the fruit are clarified. The seeds of all these species have voluminous perisperm, scarce endosperm, and an undeveloped embryo. Fruit characters in Peperomia can be useful for identifying the species of this genus. However, a thorough search in more species is suggested for additional characters or character states.
\end{abstract}

Key words: anatomy, morphology, pericarp, pseudocupule, stigma, style.

$\boldsymbol{P}$ eperomia Ruiz et Pavón comprende un número indeterminado de especies que se distribuyen en las regiones tropicales y subtropicales de ambos hemisferios (Jones, 1988; McKendrick, 1992; Thorne, 1992). Este género presenta flores diminutas, apétalas, zigomorfas, hipogíneas, perfectas, subtendidas por una bráctea y agrupadas en espigas (Dodson y Gentry, 1978; Cronquist, 1981; McKendrick, 1992; Tucker et al., 1993; Nyffeler y Rowley, 2002). El gineceo es apocárpico, monocarpelar, unilocular, con placentación basal y con un óvulo sésil, ortótropo, crasinucelado y unitégmico (Johnson, 1900, 1902, 1914; Murty, 1952; Tucker, 1980; Nikiticheva, 1981).
Uno de los motivos que atrae el interés hacia Peperomia es la dificultad para determinar sus especies (Hill, 1907; Trelease, 1922; Yuncker, 1958; Burger, 1971; Cronquist, 1981; McKendrick, 1992; Wanke et al., 2006), lo cual se explica por el conocimiento parcial de los estudios realizados para este género, además de un muestreo de especies limitado y algunas veces redundante (Hill, 1907; Trelease, 1922; Standley y Steyermark, 1952; Burger, 1971).

El objetivo de esta investigación es describir el fruto y la semilla de algunas especies de Peperomia presentes en México. Los caracteres observados se comparan con los consignados en la literatura especializada del género con el 
fin de señalar caracteres nuevos y para unificar la terminología y el método de examen de la estructura del fruto y la semilla.

El fruto y la semilla de Peperomia se describen generalmente con base en la observación de ejemplares de herbario; sin embargo, en este tipo de material el proceso de secado puede alterar o eliminar características (Burger, 1971). Este efecto se puede superar con el uso de frutos y semillas fijados en campo.

El fruto y la semilla de Peperomia han sido poco estudiados y su valor taxonómico es opacado por el de las estructuras vegetativas (Yuncker, 1950; Standley y Steyermark, 1952; Burger, 1971; McKendrick, 1992; Nyffeler y Rowley, 2002). Inclusive se han descrito especies nuevas sin el conocimiento del fruto (Yuncker, 1950, 1956, 1961; Rauh y Barthtlott, 1975; Görts-Van Rijn, 1988; Pino et al., 2003).

Algunos autores han señalado la utilidad del fruto para clasificar e identificar las especies de este género (Miquel, 1843; Candolle, 1869; Dahlstedt, 1900; Hill, 1906, 1907; Trelease, 1922; Yuncker, 1936, 1974; Trelease y Yuncker, 1950; Valdebenito, 1988; Valdebenito et al., 1992). Con base en las características del fruto, Dahlstedt (1900) estableció los subgéneros Acrocarpidium, Erasmia, Micropiper, Ogmocarpidium, Panicularia, Pleurocarpidium, Rhyncophorum, Sphaerocarpidium y Tildenia (Trelease y Yuncker, 1950; McKendrick, 1992; Valdebenito et al., 1992).

La estructura seminal de Peperomia se considera constante
(Jonhson, 1900, 1914; Hill, 1906; Corner, 1976; Takhtajan, 1988). Sin embargo, las características de su saco embrional (tetraspórico, 16-nucleado) son diferentes de las del tipo normal o Polygonum (monospórico, 8-nucleado) (Campbell, 1899; Johnson, 1900, 1902, 1914; Brown, 1908; Maheshwari y Kapil, 1966), y esto genera especulación sobre la evolución del megagametofito en las angiospermas (Gvaladze y Akhalkatsi, 1990, 1998). Por esta razón, el estudio embriológico de Peperomia se centra comúnmente en los eventos de megasporogénesis y megagametogénesis.

\section{Materiales y métodos}

Se recolectaron frutos en poblaciones silvestres de 17 especies mexicanas de Peperomia, las cuales representan seis subgéneros (cuadro 1). Para eliminar el efecto del secado de los ejemplares de herbario sobre las características del fruto y la semilla de Peperomia, en el presente trabajo se utilizaron frutos fijados en el campo en FAA durante 1 a 30 días, y conservados en glicerol +2 -propanol + agua $(25$ $+50+25)($ GAA). Las descripciones se basan en frutos maduros, a menos que se indique otra edad.

Para las observaciones anatómicas, el material almacenado en GAA se enjuagó, deshidrató e incluyó en parafina. Se obtuvieron cortes longitudinales y transversales de 10 $\mu \mathrm{m}$ de grosor con un micrótomo rotatorio.

Los cortes se desparafinaron y algunos se tiñeron con

Cuadro 1. Especies estudiadas de Peperomia arregladas por subgéneros con base en Dahlstedt (1900). Se señala forma de crecimiento, número del recolector (MAMC) y localidad.

\author{
I. Acrocarpidium (Miq.) Hensch. \\ II. Ogmocarpidium Dahlst. \\ III. Tildenia Miq.
}

IV. Rhyncophorum (Miq.) Dahlst.

V. Sphaerocarpidium Dahlst.

VI. Micropiper (Miq.) Dahlst.

\author{
1. P. hispidula (Sw.) A.Dietr. Geófita, 001, Texcoco, México. 018, Texcoco, México. \\ 2. P. pellucida (L.) Kunth Terrestre, 046, Teapa, Tabasco. \\ 3. P. campylotropa A.W.Hill Geófita, 019, Texcoco, México. \\ 4. P. cordovana C.DC. Geófita, 074, Tetipac, Guerrero. \\ 5. P. hintonii Yunck. Terrestre, 020, Mineral del Monte, Hidalgo. \\ 6. P. mexicana (Miq.) Miq. Geófita, 025, Acajete, Veracruz. \\ 7. P. collocata Trel. Epífita y terrestre, 002, Acajete, Veracruz. 027, Acajete, Veracruz. \\ 8. P. macrostachya (Vahl) A.Dietr. Epífita y terrestre, 028, Xico, Veracruz. 071, Xico, \\ Veracruz. \\ 9. P. magnoliaefolia (Jacq.) A.Dietr. Epífita, 052, Macuspana, Tabasco. \\ 10. P. obtusifolia (L.) A.Dietr. Epífita y terrestre, 003, Xico, Veracruz. 029, Xico, \\ Veracruz.
}

11. P. donaguiana C.DC. Terrestre, 006, Tenango de Doria, Hidalgo. 037, Tenango de Doria, Hidalgo.

12. P. galioides Kunth Epífita, 021, Vega de Ramírez, Veracruz.

13. P. limana Trel. et Standl. Terrestre, 010, Tetipac, Guerrero. 044, Tetipac, Guerrero.

14. P. rotundifolia (L.) Kunth Epífita, 061, Palenque, Chiapas.

15. P. deppeana Schltdl. et Cham. Epífita, 035, Tenango de Doria, Hidalgo.

16. P. quadrifolia (L.) Kunth Epífita, 060, Palenque, Chiapas. 065, Palenque, Chiapas.

17. P. tetraphylla (G.Forst.) Hook. et Arn. Epífita, 009, Tetipac, Guerrero. 043, Tetipac, Guerrero. 
Cuadro 2. Caracteres y estados de carácter en el fruto de Peperomia.

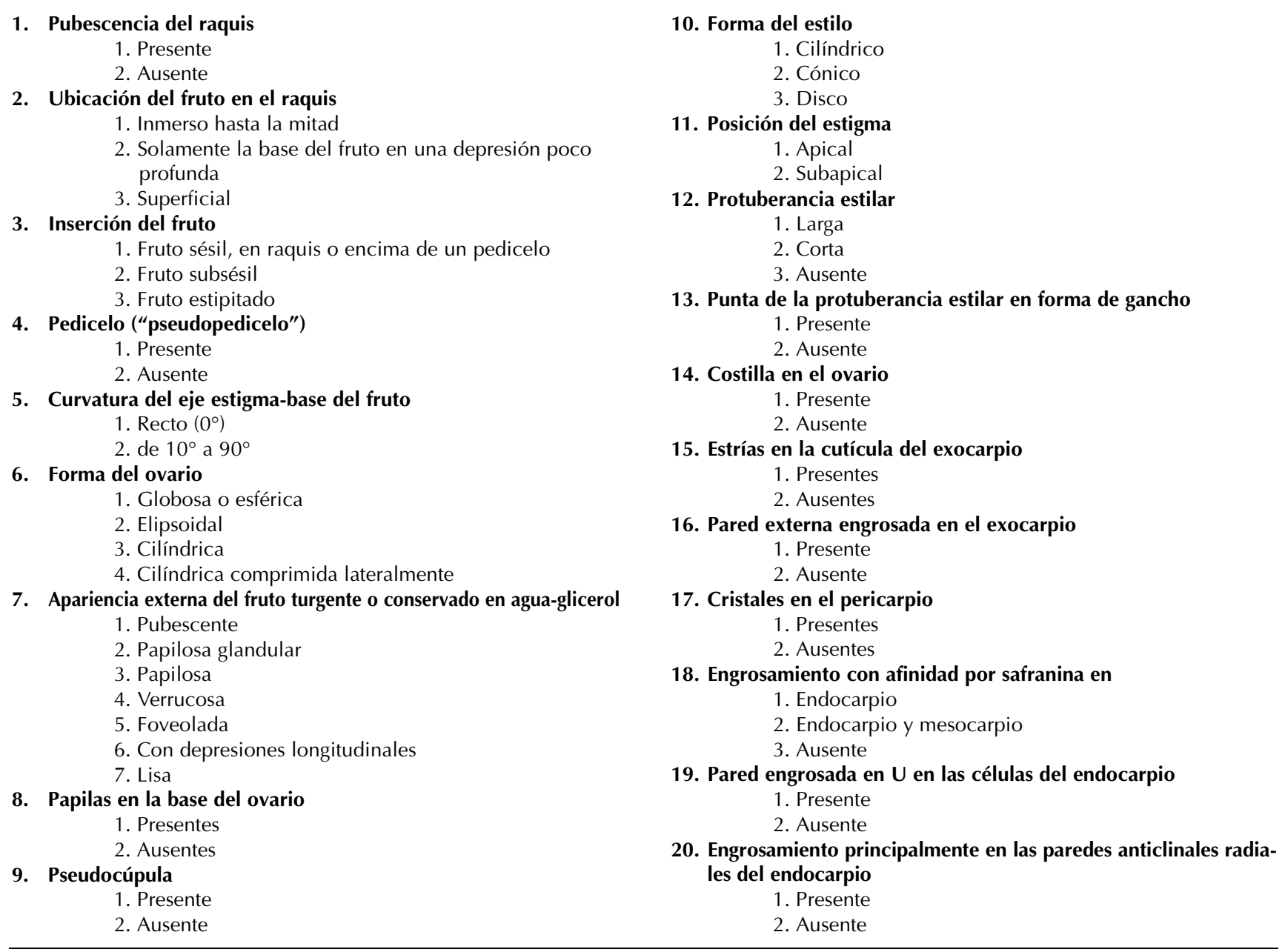

una receta de safranina saturada desarrollada por el Dr. E. M. Engleman (safranina “ $\mathrm{O}$ ” $0.5 \mathrm{~g} ; \mathrm{NaCl} 20 \mathrm{~g}$ y agua 1,000 $\mathrm{ml}$ ) y verde fijo (solución de $0.12 \% \mathrm{p} / \mathrm{v}$ de verde fijo FCF en alcohol etílico 96\%), y se montaron en resina.

En otros cortes desparafinados se identificaron cutículas. Éstos se llevaron hasta alcohol al 70\%, se tiñeron con fat red $7 \mathrm{~B}(0.05 \mathrm{~g}$ de fat red $7 \mathrm{~B}$ disuelto con calor en alcohol butílico $25 \mathrm{ml}+$ etilenglicol $75 \mathrm{ml}$ ) durante $6 \mathrm{~h}$ en un recipiente cerrado, y se montaron en grenetina glicerinada (10\% grenetina, $50 \%$ glicerol, $1 \%$ fenol y $39 \%$ agua).

Para las observaciones morfológicas, algunos frutos enteros almacenados en GAA fueron teñidos con fat red 7B para identificar lípidos y cutículas. En este caso los frutos se lavaron en agua $(1 \mathrm{~h})$ y se sumergieron en fat red $7 \mathrm{~B}$, en donde se mantuvieron durante una semana hasta su observación por estereomicroscopía. Se hicieron cortes manuales del pericarpo de estos frutos y se montaron en glicerol. Los detalles de la apariencia externa del fruto, así como la posición y la distribución de los ornamentos fueron observados en un microscopio de luz.

\section{Resultados}

Fruto. En el cuadro 2 se presenta una lista de los caracteres y estados de carácter encontrados. El fruto es indehiscente, monospermo, con placentación basal y simetría bilateral. Se distinguen el estigma, el estilo y el ovario o cuerpo (figuras 1, 2, 5). En la mayoría de las especies el tejido de los frutos conservados en GAA es translúcido, por lo que la estructura externa de la semilla se puede observar con algún detalle dentro del fruto (figuras 2-7, $11-13,19,21,22,27,29)$, al igual que el canal estilar que va desde el estigma hasta el micrópilo de la semilla (figuras 4-7, 21, 28).

Los frutos son generalmente víscidos y se observan comúnmente adheridos a la espiga (figura 10). El sentido de la diferenciación de los frutos en la espiga es acrópeta. El raquis es glabro (figuras 18, 24) o pubescente (figuras 26, 29), y puede presentar depresiones. Los frutos se ubican en el raquis: (i) inmersos hasta la mitad (figura 29), (ii) inmersos sólo en la base en una depresión poco profunda 

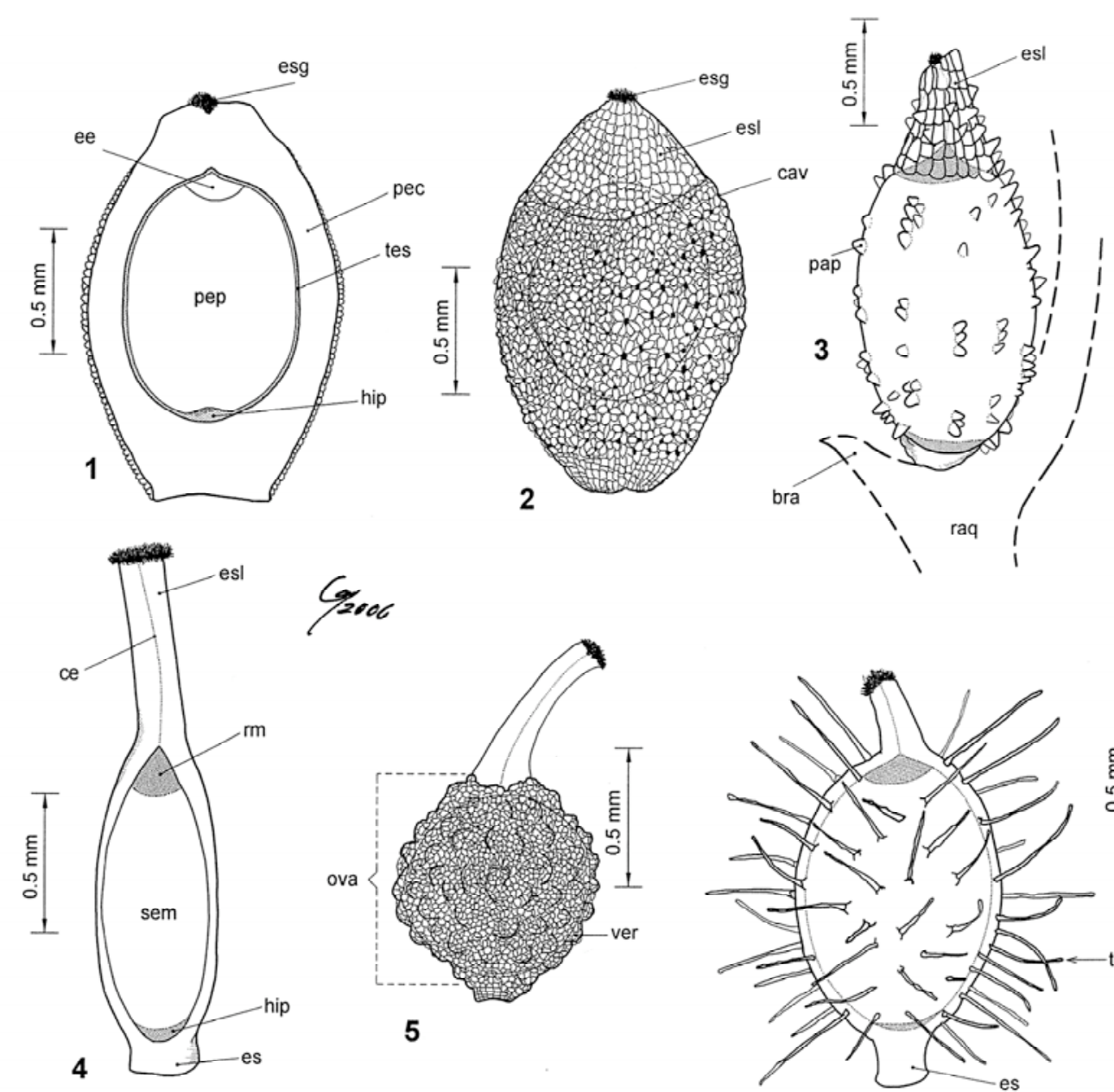

5
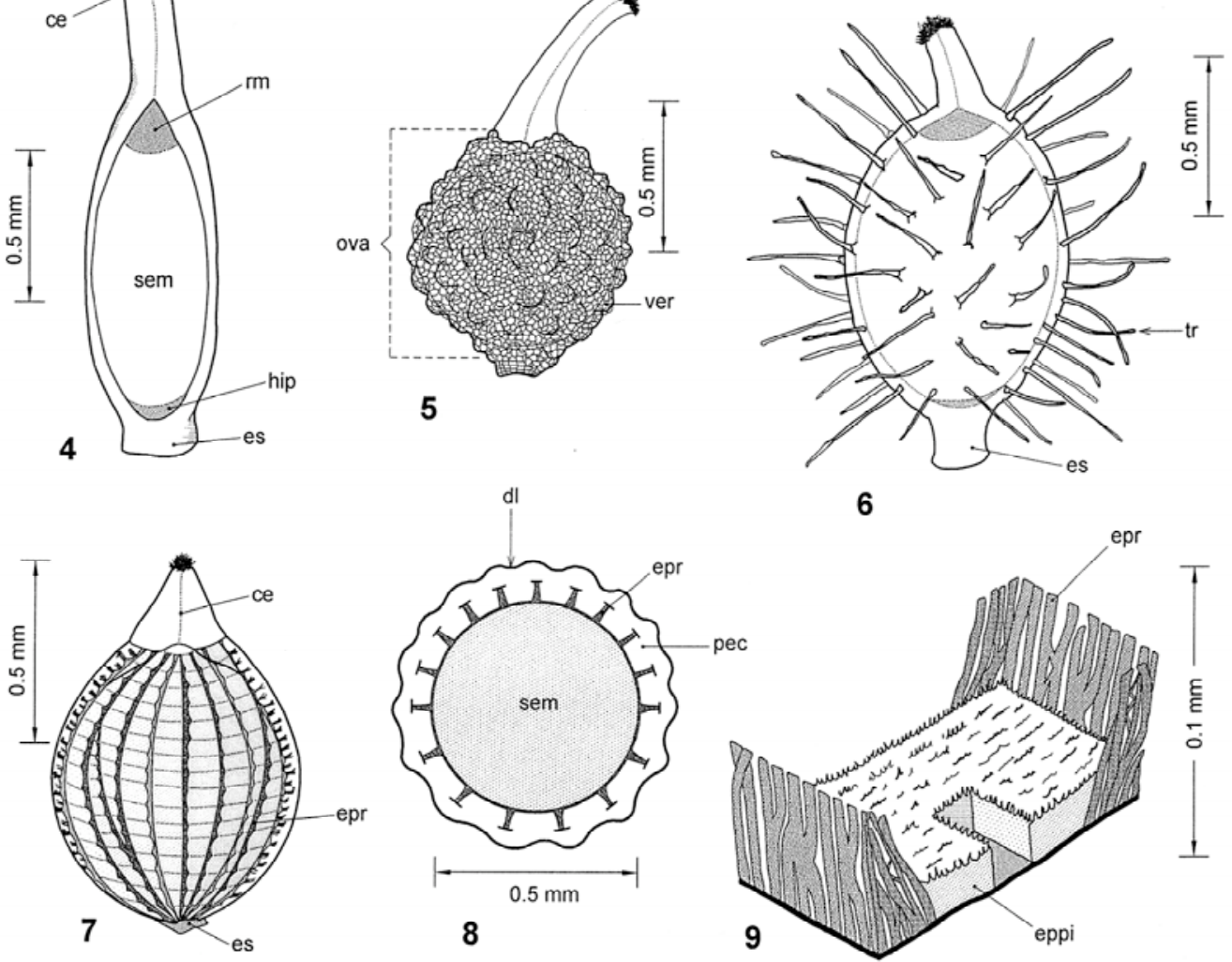

6

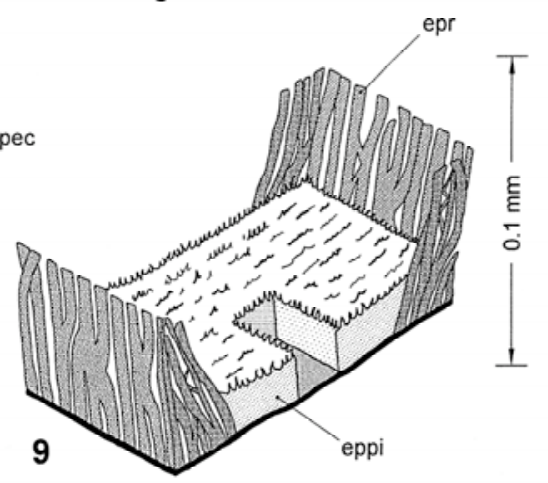

Figuras 1-9. 1. Peperomia campylotropa. Corte mediano del fruto maduro. 2. P. campylotropa. Vista externa del fruto con el contorno de la semilla adentro. 3. P. hintonii. Vista externa del fruto, la semilla madura ocupa todo el ovario. Ápice de la espiga hacia arriba. Las papilas presentan un arreglo irregular en la superficie del fruto. 4. P. mexicana. Corte mediano del fruto maduro. 5. P. cordovana. Vista externa del fruto con el contorno de la semilla adentro. Ápice de la espiga hacia la izquierda. 6. P. hispidula. Vista externa del fruto con corte mediano de la semilla adentro. 7. P. pellucida. Vista externa del fruto con engrosamientos de las paredes radiales del endocarpio. La semilla madura ocupa todo el ovario. 8. P. pellucida. Corte transversal del fruto con engrosamientos de las paredes radiales del endocarpio. 9. Diagrama en tres dimensiones de una célula del endocarpio de P. pellucida. Las paredes radiales, y partes de las transversales, contienen bandas orientadas en sentido radial. Las bandas se anastomosan.

Acotaciones. bra, bráctea; cav, cavidad; ce, canal estilar; dl, depresión longitudinal; ee, sitio que ocupan el embrión y el endospermo; eppi, engrosamiento de la pared periclinal interna de las células del endocarpio; epr, engrosamiento de la pared radial de las células del endocarpio; es, estípite; esg, estigma; esl, estilo; hip, hipostasa; ova, ovario; pap, papila; pec, pericarpio; pep, perispermo; raq, raquis; rm, región micropilar; sem, semilla; tes, testa; tr, tricoma; ver, verruga. 
(figuras 12, 21, 22, 24, 28), (iii) de manera superficial (figura 3), o (iv) en estípites (figura 6). Los frutos son: (i) sésiles (figuras 2, 11, 12, 17, 19, 21, 22, 27, 29), (ii), subsésiles (figuras 3-5, 7, 13), o (iii) estipitados (figuras 6, 15). En $P$. rotundifolia, algunos frutos en la misma espiga se elevan del raquis por estructuras semejantes a estípites (figura 18); algunos autores reconocen estas estructuras como pseudopedicelos (Yuncker, 1936, 1950, 1974; Burger, 1971; Steyermark, 1984).

En los frutos se puede trazar un eje imaginario entre el estigma y la base del fruto (cicatriz de abscisión) (figuras 11, 13). La orientación o curvatura del eje estigma-base del fruto es comúnmente recta (cero grados de curvatura) (figuras 2 , $4,11,12,21,22$ ), pero en algunas especies la curvatura de este eje es de aproximadamente $30^{\circ}$ (figuras 13,19 ).

Las formas del ovario son: (i) globosa o esférica (figuras $5,7,11,13,19,20$ ), (ii) elipsoidal (figuras 2, 3, 6, 12, 21, 29), (iii) cilíndrica (figuras 4, 27, 28), y (iv) cilíndrica comprimida lateralmente (figuras 22, 23).

La apariencia externa de los frutos puede ser: (i) pubescente (figura 6), (ii) papilosa glandular (figuras 11, 12, 13, 19), (iii) papilosa (figura 3), (iv) verrucosa (figura 5), (v) foveolada (figura 2), (vi) con depresiones longitudinales (figuras 7, 8), y (vii) lisa (figuras 4, 21, 22, 24, 27-29). La apariencia externa de los frutos se relaciona con las características de las células en el exocarpio.

Cuando se tiñe la cutícula externa del fruto se resaltan irregularidades como papilas en la base del ovario (figura 21). En algunos frutos se observa una cutícula gruesa roja que puede cubrir desde la base del fruto hasta su parte media (figura 29), o sólo una porción de la base del ovario (figuras 27 y 28). Esta cutícula gruesa (figura 31) es la "pseudocúpula" del subgénero Micropiper (Dahlstedt, 1900; Yuncker, 1936, 1974; McKendrick, 1992).

Estilo. En todas las especies se identifica una zona gruesa del pericarpio entre la semilla y el estigma, que se nombra estilo en sentido amplio. La superficie estilar se diferencia del ovario por la textura de la superficie (figuras 2, 7), por no presentar células secretoras (figura 12), o por una constricción en su base (figuras 4-6). El estilo puede ser: (i) cilíndrico (figuras 4-6, 21, 27, 29, 30), (ii) cónico (figuras 2, 3, 7,28 ), o (iii) apreciado como un engrosamiento apical estigmatífero en forma de disco ("estilopodio" en el sentido de Trelease, 1922) (figuras 11-14, 19, 20, 22, 23).

Estigma. El estigma es la región para la germinación de los granos de polen, en la que la protodermis se diferencia en una epidermis glandular (figuras 1, 2, 30). La posición del estigma es una característica variable entre especies. El estigma en la posición apical (figuras 2-7, 28, 29) se encuentra en el extremo del estilo, mientras que el estigma subapical se encuentra sobre la superficie apical oblicua del estilo (figura 27), o comúnmente en la base de una protu- berancia (figuras 11-13, 19, 21, 22, 24, 30).

La protuberancia se ori gina en el borde del estilo opuesto al estigma (figura 30), como una proyección del estilo. La protuberancia estilar es denominada "pico" por unos autores (Trelease, 1922; Yuncker, 1950; Boufford, 1982; Steyermark, 1984). Los términos corto y largo se refieren a la longitud relativa de la protuberancia entre las especies que la presentan: (i) protuberancia estilar larga (fig u ras 21, 24) y (ii) protuberancia estilar corta (figu ras 11-13, 19, 22). En el fruto, la protuberancia se ubica en el lado opuesto a la posición de la bráctea y los estambres (figuras 18, 24, 25), y puede presentar un ensanchamiento decurrente en su base a 1 rededor del estigma (fi gu ras 14, 20, 23).

La punta de la protuberancia estilar de P. obtusifolia (figura 21) tiene forma de gancho, a diferencia de $P$. collo cata y $P$. magnoliaefolia (figura 24) que tienen la punta recta.

P. tetraphyla presenta un engrosamiento del pericarpio, que se difunde del estilo hasta el ovario en un sector limitado de la periferia, a manera de costilla (figura 29). La costilla se ubica en el lado del fruto orientado hacia la bráctea (figura 26).

Pericarpio. El pericarpio rodea la semilla (figura 1). Las capas del pericarpio (figura 36) son: exocarpio, mesocarpio y endocarpio. Se presenta un haz vascular en el mesocarpio en lado del fruto que se orienta hacia la bráctea. La posición del haz vascular evidencia la simetría bilateral del fruto de Peperomia, aun en los frutos de las especies con ovarios globosos o elipsoidales y que no presentan una protuberancia estilar o una costilla (figuras 2-7). Los miembros de vaso presentan engrosamientos anulares o helicoidales (figuras 31, 41).

Exocarpio y mesocarpio. En algunas especies, desde la floración hasta la madurez, se observan estrías en la cutícula del exocarpio (figuras 35, 36).

La epidermis de $P$. hispidula presenta tricomas, que producen la apariencia pubescente del fruto (figura 6).

En la superficie papilosa glandular (figura 12), el término papila se aplica a una célula emergente que contiene lípidos en su lumen (figuras 32, 33); su ápice se desprende comúnmente durante la microtecnia. A diferencia de $P$. hin tonii, la "papila" no es glandular (figuras 3, 34). En los frutos con apariencia verrucosa (figura 5) se observan protuberancias pluriestratificadas que se producen por divisiones periclinales de la epidermis (figura 35).

En $P$. campylotropa (figura 2) se aprecian cavidades en la epidermis del fruto (figura 36).

En las células del exocarpio de algunas especies se presenta la pared externa engrosada (figura 36), la cual se manifiesta desde los estadios tempranos de desarrollo del fruto.

En el mesocarpio de $P$. deppeana (figura 37 ) y $P$. macrostachya se observan cristales hacia la base de fruto. 

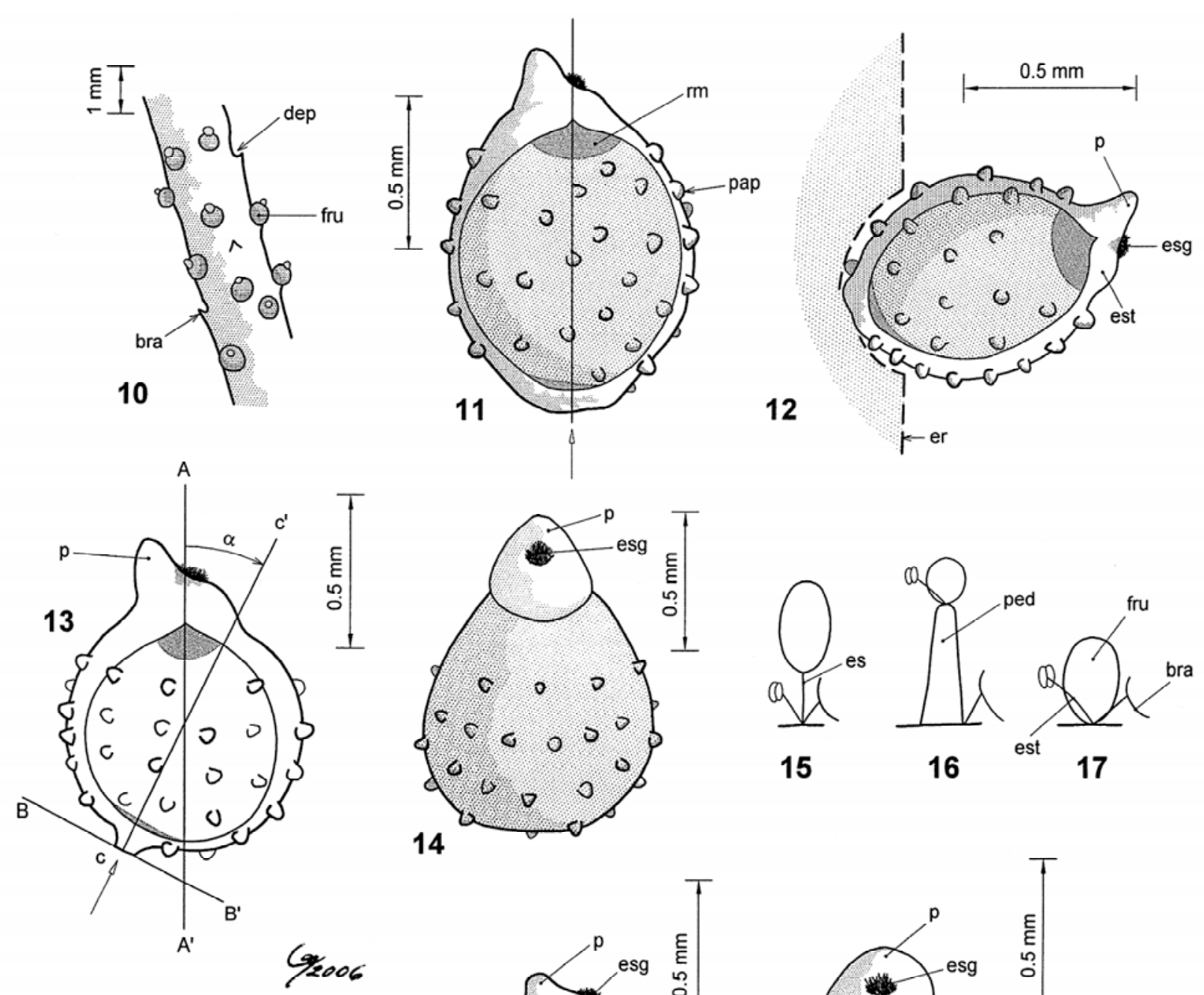

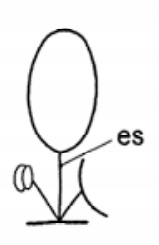

15

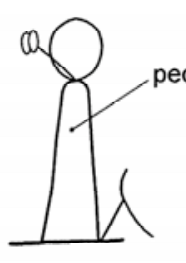

16

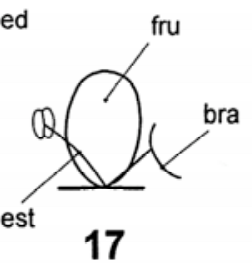

14
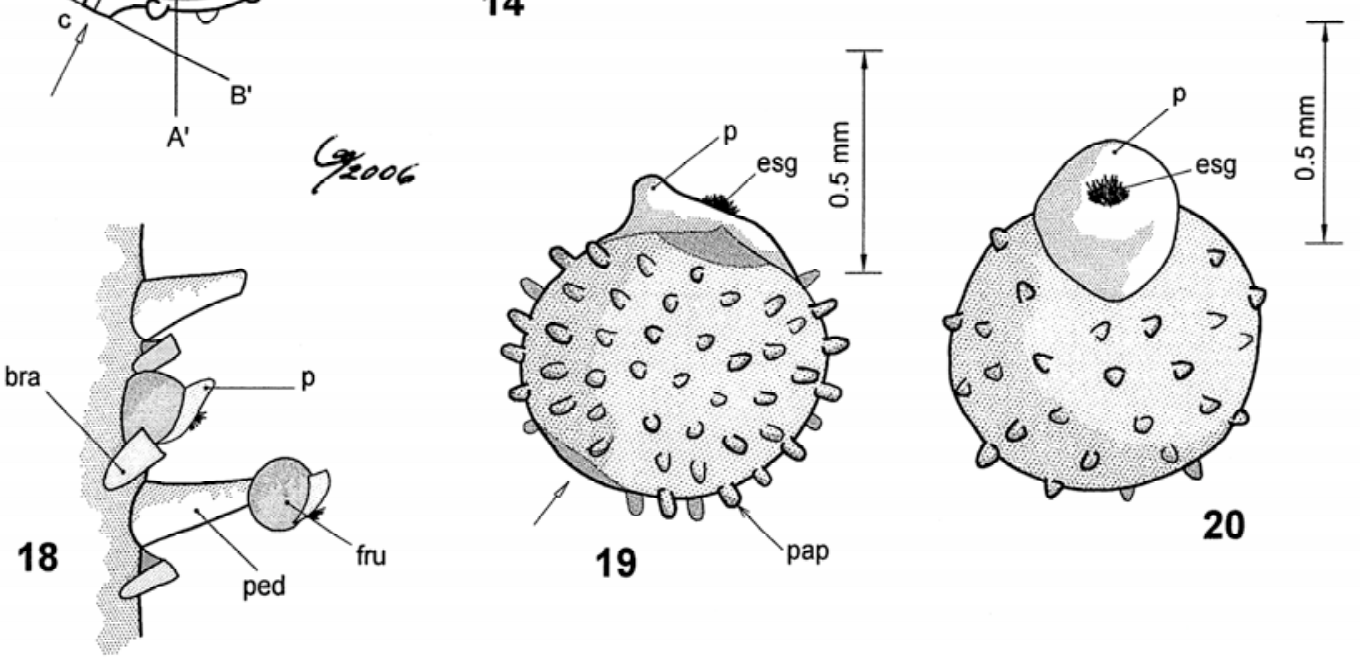

Figuras 10-20. 10. Peperomia limana. Segmento de una espiga, ápice hacia arriba. 11. P. limana. Fruto con una apariencia externa papilosa glandular. Ápice de la espiga hacia la izquierda. 12. $P$. donaguiana. Fruto ligeramente hundido en el raquis. Ápice de la espiga hacia arriba. La bráctea de la base del fruto no se dibuja. 13. P. galioides. Fruto y semilla con ejes curvos, para medir la curvatura del eje base del fruto-estigma, se traza una línea (BB') en el plano del hilo y base del fruto (zona de abscisión del fruto). Se traza una línea perpendicular a BB' (CC') en el centro de la base del fruto. Se traza una línea del estigma por el embrión (AA'). Se mide el ángulo $\alpha$ entre AA' y CC'. Ápice de la espiga hacia la izquierda. 14. P. galioides. Vista del lado opuesto a la protuberancia estilar. 15-17. Diagramas exagerados de la inserción de los frutos en la espiga. 15. Fruto estipitado. 16. Fruto sobre un pedicelo. 17. Fruto sésil. 18. P. rotundifolia. Segmento de una espiga. Ápice de la espiga hacia arriba. 19. P. rotundifolia, curvatura del eje base del fruto-estigma similar a $P$. galioides (Fig. 13). Ápice de la espiga hacia la izquierda. 20. . rotundifolia . Vista del lado opuesto a la protuberancia estilar. Flecha = posición de cicatriz de abscisión.

Acotaciones. bra, bráctea; dep, depresión; er, epidermis del raquis; es, estípite; esg, estigma; esl, estilo; est, estambre; fru, fruto; p, protuberancia estilar; pap, papila; ped, pedicelo; rm, región micropilar. 


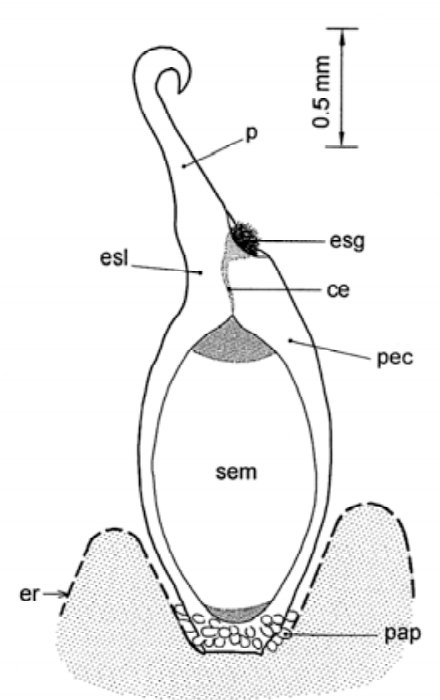

21

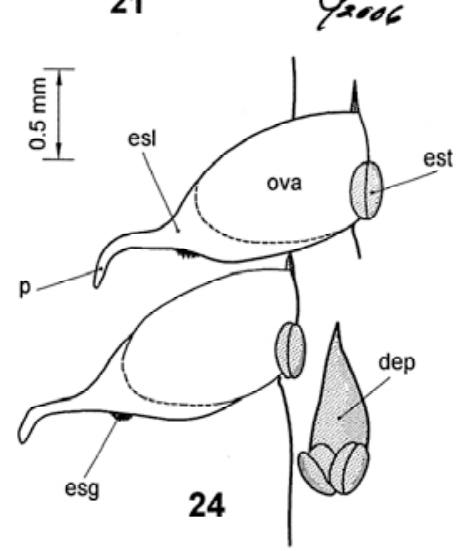

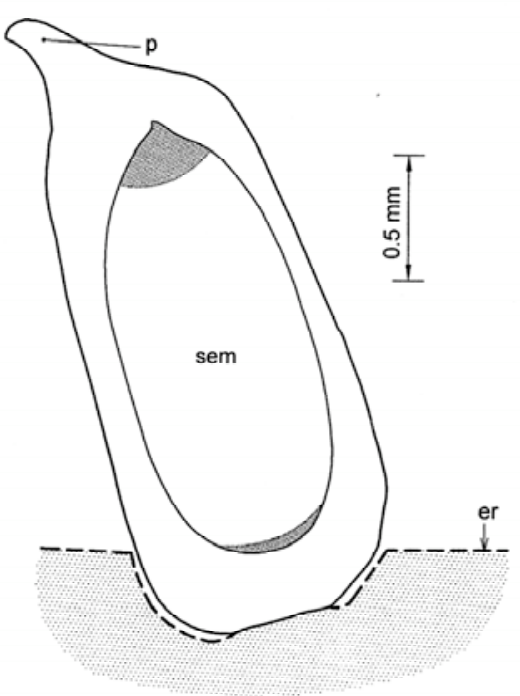

22

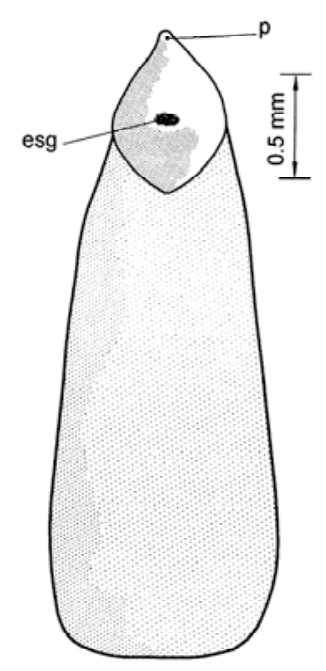

23

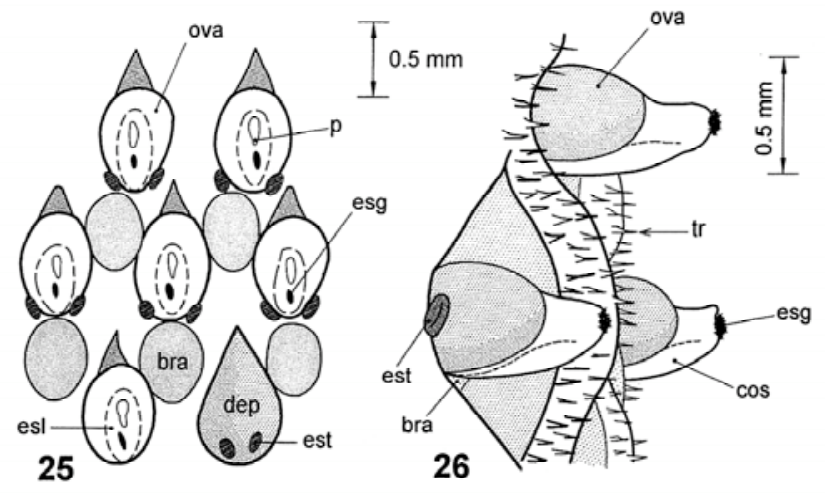

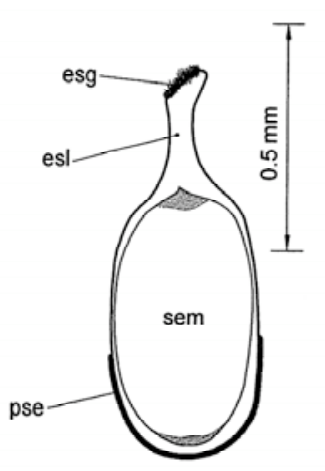

27
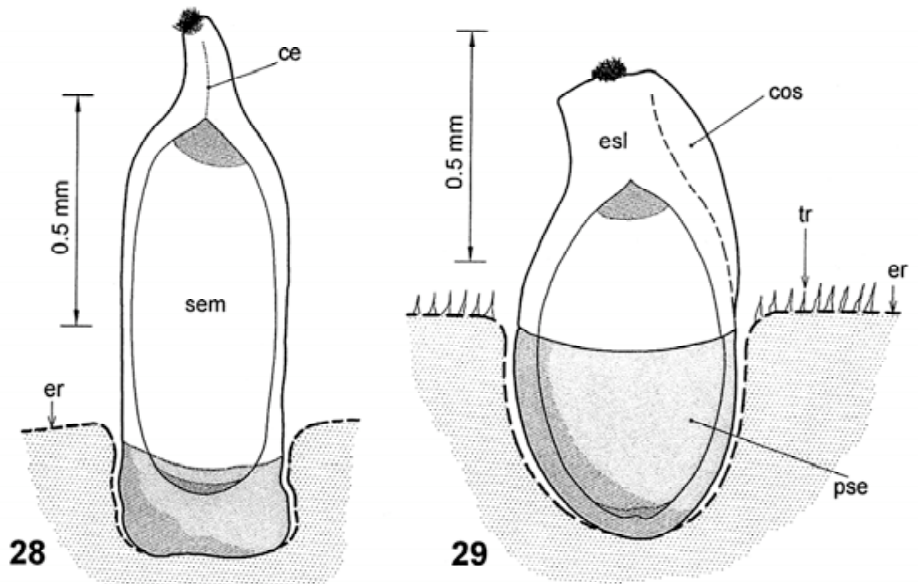

Figuras 21-29. 21. Peperomia obtusifolia. Corte mediano del fruto. Ápice de la espiga hacia la izquierda. 22. P. macrostachya. Corte mediano del fruto. Ápice de la espiga hacia la izquierda. 23. P. macrostachya. Vista del lado opuesto a la protuberancia estilar. 24. P. mag noliaefolia. Ubicación de frutos en la espiga, ápice hacia arriba. Vista lateral. La bráctea en la base del fruto no se dibuja. 25. P. magno liaefolia. Vista apical de un segmento de la espiga. Ápice de la espiga hacia arriba. 26. P. tetraphyla. Ubicación de frutos en la espiga, ápice hacia arriba. Vista lateral. 27. P. quadrifolia. Corte mediano del fruto maduro. Ápice de la espiga hacia la izquierda. 28. $P$. dep peana. Vista externa del fruto con corte mediano de la semilla adentro. Ápice de la espiga hacia la izquierda. 29. P. tetraphyla. Vista externa del fruto con corte mediano de la semilla adentro. Ápice de la espiga hacia la izquierda.

Acotaciones. bra, bráctea; ce, canal estilar; cos, costilla; dep, depresión; er, epidermis del raquis; esg, estigma; esl, estilo; est, estambre; ova, ovario; p, protuberancia estilar; pap, papila; pec, pericarpio; pse, pseudocúpula; sem, semilla; tr, tricoma. 
Endocarpio. Algunas especies presentan paredes anticlinales que muestran punteaduras redondas o alargadas en sentido perpendicular al endocarpio (figura 39). Las paredes engrosadas se tiñen con safranina. En algunas especies, la células del mesocarpio también presentan el engrosamiento de sus paredes ( $P$. collocata, $P$. deppeana, $P$. magnoliaefolia, $P$. rotundifolia). Las células del endocarpio de $P$. limana manifiestan además una pared gruesa, sin punteaduras y teñida de verde, que ocupa la zona periclinal interna de la célula y la mitad de cada pared anticlinal (engrosamiento en "U', figura 40).

En P. pellucida se aprecian engrosamientos en bandas que cubren las paredes anticlinales radiales y parte de las transversales (figuras 7-9, 42). En la pared periclinal interna se observa un engrosamiento de textura granular y con proyecciones irregulares hacia el lumen (figuras 9, 42).

Semilla. La semilla presenta un embrión poco desarrollado, poco endospermo y gran cantidad de perispermo amiláceo (figuras 1, 38). El perispermo es el principal tejido de reserva y se origina de la nucela del óvulo. En la base de la semilla se observa una hipostasa (figuras 1,4), que es una zona de protección en forma de disco, sin espacios intercelulares, y cuyas células contienen taninos (Espinosa-Osornio y Engleman, 1998). Las zonas del micrópilo y de la hipostasa se identifican por la coloración más oscura que el resto de la semilla (figura 4). La posición del hilo siempre coincide con la cicatriz del fruto.

La testa (figuras 1,38) se deriva del tegumento del óvulo y muestra en la madurez uno o dos estratos. La exotesta con un solo estrato de células siempre se manifiesta, pero ocasionalmente puede identificarse una endotesta que proviene de la epidermis interna del tegumento. En ambos estratos las células acumulan taninos. Las células cercanas al micrópilo presentan proyecciones lobuladas hacia el endospermo (figura 34).

Las semillas observadas fueron: esféricas (figuras 2, 5, 13) o elipsoidales (figuras 3, 4, 12, 21, 22, 27-29). En una misma especie se puede presentar una graduación entre los dos tipos. La mayoría de las semillas son simétricas con respecto al eje longitudinal entre el micrópilo y el hilo. En los frutos con una curvatura del eje estigma-base del fruto de $30^{\circ}$, el lado opuesto a la protuberancia estilar es el más extenso (figuras 13, 19).

\section{Discusión}

Las 17 especies estudiadas de Peperomia se diferencian con base en 20 caracteres del fruto. En la literatura del género, los caracteres 1-7 y 9-13 se registran generalmente como características descriptivas, con un valor taxonómico limitado (Trelease, 1922; Yuncker, 1950, 1974; Standley y Steyermark, 1952; Burger, 1971; Steyermark, 1984). Los caracteres 8 y 14-20 se introducen en este trabajo. Además, se precisan las descripciones anteriores de los caracteres 17 y 9-13, y sus estados de carácter.

La presencia de la costilla en el fruto (carácter 14) se registra ocasionalmente. Los caracteres 16 y 18 (paredes en exocarpio y pared safraninófila en pericarpio) son descritos en algunos trabajos anatómicos sobre el fruto de Peperomia y se relacionan con la especialización de crecimiento xerófilo (Johnson, 1900; Hill, 1906, 1907).

La presencia del engrosamiento en la pared de las células del endocarpio (caracteres 18, 19 y 20) determina que los frutos se clasifiquen como drupas (Yuncker, 1950, 1974; Burger, 1971; Steyermark, 1984), y cuando carecen de engrosamientos, como bayas (Dahlsted, 1900; Trelease, 1922).

Los caracteres $8,15,17,19$ y 20 son nuevos para este género. La presencia de estrías en la cutícula del exocarpio (carácter 15) está ampliamente distribuida en las especies estudiadas del subgénero Tildenia y en especies de Micropiper (P. quadrifolia), Sphaerocarpidium (P. limana), y Acrocarpidium (P. hispidula).

La inserción del fruto en el raquis (carácter 3), la forma del ovario (carácter 6), la apariencia externa del fruto (carácter 7), la presencia de la pseudocúpula (carácter 9), la forma del estilo (carácter 10), la posición del estigma (carácter 11) y la protuberancia estilar (carácter 12) destacan a primera vista como los caracteres más contrastantes. Estos caracteres se utilizan para definir los subgéneros (Miquel, 1843; Dahlstedt, 1900, McKendrick, 1992) o las especies de Peperomia (Hill, 1907; Trelease, 1922; Yuncker, 1936, 1950, 1974; Trelease y Yuncker, 1950, Calderón y Rzedowski, 2001).

El fruto estipitado y la pseudocúpula son señalados como caracteres diagnósticos de los subgéneros Acrocarpidium y Micropiper, respectivamente (Dahlstedt, 1900; Trelease y Yuncker, 1950; Yuncker, 1974). Otros autores muestran la punta de la protuberancia estilar en forma de gancho (carácter 13) como un carácter útil para diferenciar especies de Rhyncophorum, cuando las estructuras vegetativas son similares (Yuncker, 1950, 1974; Steyermark, 1984).

Los términos "estípite" y "pedicelo" se señalan como sinónimos por otros autores (Yuncker, 1974; Steyermark, 1984). En el presente trabajo, los términos "estípite" y "pedicelo" se aplican a estructuras diferentes (ver cuadro 2 , caracteres 3 y 4). El estípite (ginóforo) es el eje que sostiene el pistilo y en su base se encuentran los estambres (figura 15). La característica de fruto subsésil señala la presencia de un estípite pequeño (figuras 3-5, 7, 13).

En $P$. rotundifolia las estructuras que elevan los frutos del raquis son pedicelos, que en su extremo distal sostienen dos estambres y un fruto sésil (figura 16). En el presente trabajo no se utiliza el término "pseudopedicelo", porque se considera que la estructura para la que se aplica este término es el pedicelo de la flor. 

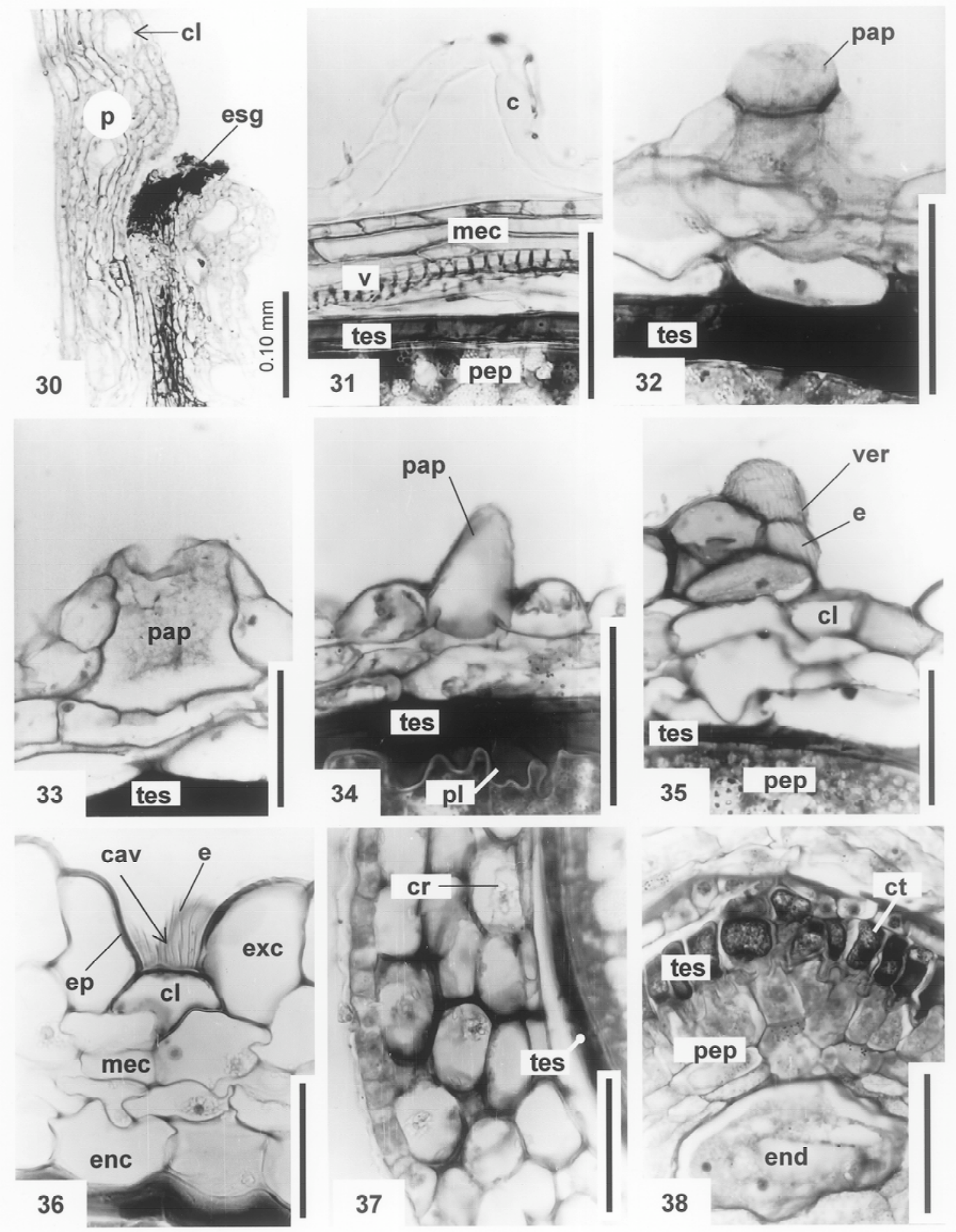

Figuras 30-38. 30. Peperomia obtusifolia. Estigma y base de la protuberancia estilar. 31. P. tetraphyla. Pericarpio en la región de la pseudocúpula. 32. Papila glandular del exocarpio de $P$. donaguiana. 33. Papila glandular del exocarpio de $P$. galioides. 34. Papila de $P$. hintonii. Corte transversal del fruto. 35. $P$. cordovana. Corte transversal del fruto. 36. $P$. campylotropa. Corte transversal del fruto. 37 . $P$. deppeana. Base del fruto. Corte longitudinal. 38. . campylotropa. Semilla. Corte longitudinal de la zona micropilar. Barras en figuras $31-38=0.05 \mathrm{~mm}$.

Acotaciones. c, cutícula; cav, cavidad; cl, célula con lípidos; cr, cristal de oxalato de calcio; ct, célula con tanino; e, estría en la cutícula epidérmica; enc, endocarpio; end, endospermo; ep, engrosamiento de la pared del exocarpio; esg, estigma; exc, exocarpio; mec, mesocarpio; p, protuberancia estilar; pap, papila; pep, perispermo; pl, proyecciones lobuladas; tes, testa; v, vaso; ver, verruga. 

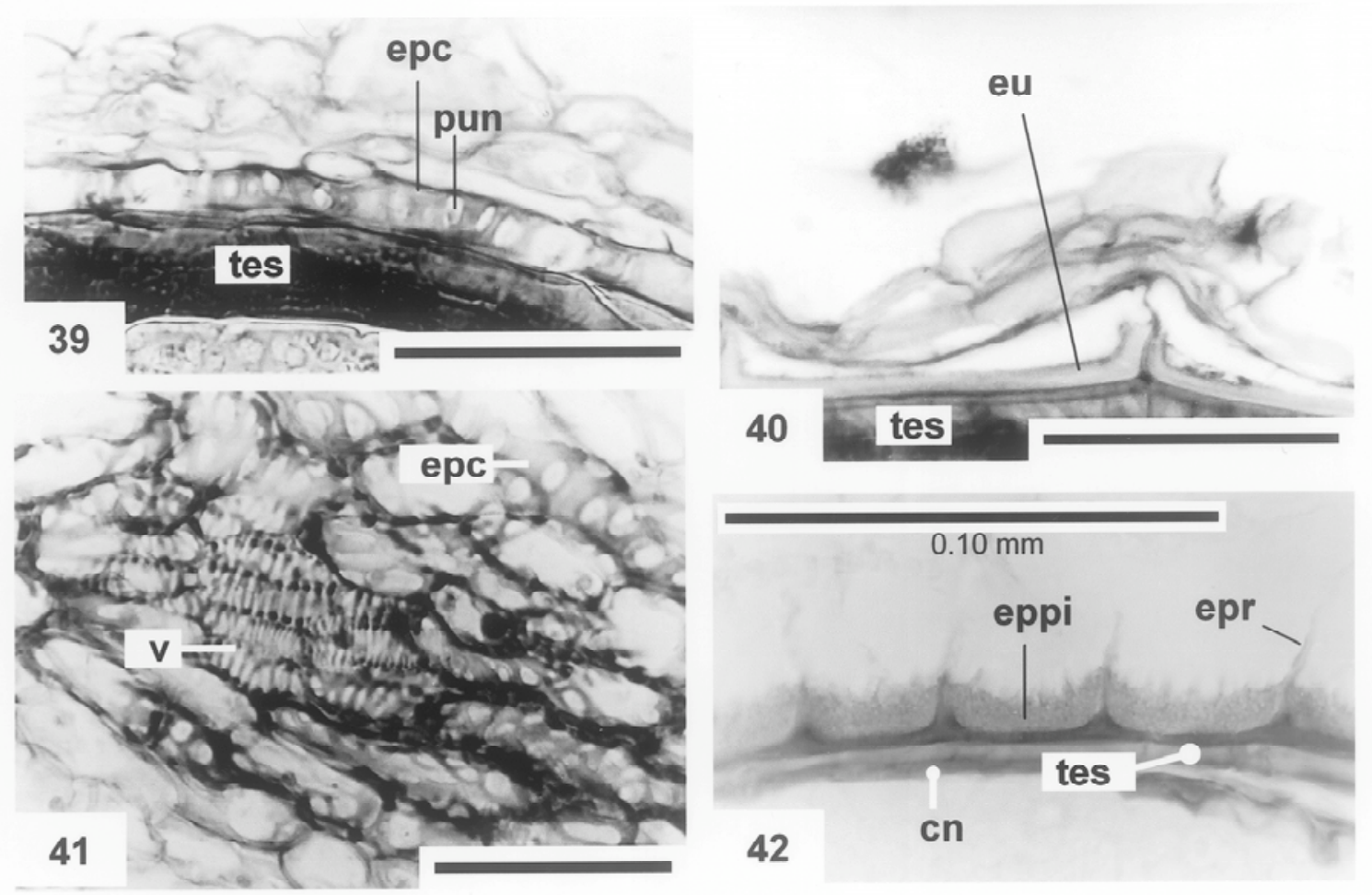

Figuras 39-42. 39. Peperomia donaguiana. Corte longitudinal. 40. P. limana. Corte longitudinal. 41. P. collocata. Corte tangencial del pericarpio. 42. P. pellucida. Corte transversal. Tinción para cutículas. Barras en figuras $39-41=0.05 \mathrm{~mm}$.

Acotaciones. cn, cutícula nucelar; epc, engrosamiento de la pared del endocarpo; eu, engrosamiento en "U"; eppi, engrosamiento de la pared periclinal interna de las células del endocarpio; epr, engrosamiento de la pared radial de las células del endocarpo; pun, punteadura; tes, testa; $\mathbf{v}$, vaso.

Burger (1971) y Steyermark (1984) consideran que la presencia del pedicelo ("pseudopedicelo") es inconsistente en los frutos de una misma espiga (figura 18) y que por ello tiene una utilidad taxonómica limitada. Con las evidencias actuales, en este trabajo se señala a Sphaerocarpidium como el único subgénero que presenta frutos pedicelados, en contraste con el concepto de Yuncker (1950, 1966, 1974), Burger (1971) y Steyermark (1984).

La curvatura del eje estigma-base del pistilo (carácter 5) (figuras 11,13) se emplea para mostrar la variación del punto de unión del fruto con el raquis, y para evitar la ambigüedad de los términos basal (figuras 11, 12), subbasal (figuras 13, 19) y lateral (Yuncker, 1974; Steyermark, 1984). Se establece una curvatura de $90^{\circ}$ con base en las observaciones de Steyermark (1984) en P. pennelli Trel. et Yunck., P. venezueliana C.DC. y P. vulcanicola C.DC.

La forma del ovario (carácter 6) y la apariencia externa del fruto (carácter 7) son caracteres muy utilizados para la descripción de taxa en Peperomia (Hill, 1907; Yuncker, 1950, 1974; Steyermark, 1984).

En ocasiones, la forma del fruto se interpreta con formas irregulares y subjetivas, cuando se considera el estilo como parte de la forma general del fruto, e.g. botella y frasco
(Trelease, 1922; Trelease y Yuncker, 1950; Barrios et al., 1987). Sin embargo, es mejor interpretar la forma del fruto con base en la forma del ovario, porque de esta manera se pueden señalar formas regulares a partir de la simetría del fruto con respecto a tres ejes (un longitudinal y dos transversales).

La forma del ova rio se relaciona con la fo rma de la semilla (figuras 3-7, 11-13, 19, 27-29). Se pueden distinguir algunos taxa con base en la forma del ovario (Hill, 1907; Trelease, 1922; Yuncker, 1950, 1974; Steyermark, 1984).

La terminología que otros autores usan para describir la apariencia externa del fruto se refiere al relieve de la superficie de frutos secos de los ejemplares de herbario (Standley y Steyermark, 1952; Yuncker, 1974; Steyermark, 1984). Esto provoca diferencias de apreciación en la aplicación de términos entre los autores, como el uso indistinto de los términos "papiloso" y "verrucoso" que se hace en algunos trabajos (Steyermark, 1984; Barrios et al., 1987; Callejas y Betancur, 1997).

La apariencia externa del fruto se altera generalmente durante la manipulación del material seco, lo cual disminu ye el valor taxonómico de este carácter (Yuncker, 1950; Steyermark, 1984). En el presente trabajo, la apariencia 
externa del fruto se determina en frutos conservados en GAA, lo cual disminuye la alteración de este carácter por la manipulación del material, y permite establecer estados de carácter más representativos del estado vivo.

Algunos autores describen la apariencia externa del fruto de P. pellucida como una red de "costillas" longitudinales interconectadas por "costillas" horizontales, con base en frutos secos, y señalan a esta característica como distintiva de esta especie y todo el subgénero Ogmocarpidium (Dahlstedt, 1900; Yuncker, 1950, 1974; Burger, 1971). En los frutos frescos o conservados en GAA de P. pellucida, el pericarpio es translúcido y las paredes anticlinales engrosadas del endocarpio se evidencian como una red interna (figuras 7, 8).

En los frutos secos, las paredes engrosadas del endocarpio provocan el levantamiento del tejido colapsado del meso- y del exocarpio, por lo que se distinguen las "costillas" resaltadas en la superficie.

Burger (1971) señala la pseudocúpula como el resultado de la diferencia de la deshidratación entre la parte superior del fruto expuesta al aire y la parte basal inmersa en el raquis. En el presente trabajo y en Wanke et al. (2006) no se apoya la propuesta de Burger.

La presencia de la pseudocúpula (carácter 9) es un carácter válido e independiente de la ubicación del fruto en el raquis (carácter 2). La pseudocúpula se identifica como una cutícula gruesa en la base de los frutos de las especies de Micropiper y no se observa en los frutos inmersos en el raquis de otras especies, e.g. $P$. donaguiana (figura 12), $P$. macrostachya (figura 22) y $P$. obtusifolia (figura 21) de los subgéneros Sphaerocarpidium y Rhyncophorum (cf. Trelease y Yuncker, 1950; Yuncker, 1936, 1950, 1974; Steyermark, 1984). No obstante, en Micropiper se aprecia una correspondencia entre la porción del fruto inmersa en el raquis y la superficie cubierta por la pseudocúpula (figuras 28, 29).

La presencia del estilo en el fruto de Peperomia es una característica que no siempre se reconoce. En algunos casos, la forma del estilo se relaciona con la forma del ápice del fruto, y se describe como domo, gorra, mamiforme, submamiforme o pico (Candolle, 1869; Hill, 1907; Yuncker, 1950, 1974; Steyermark, 1984). La característica "ápice del fruto" es artificial y ambigua, ya que ésta puede señalar: (a) la relación de la superficie distal del estilo con la presencia de la protuberancia estilar (ápice rostrado), o (b) la forma del estilo (mucronado, redondeado) (Standley y Steyermark, 1952). En el presente trabajo no se utiliza el término "estigma sésil" (ver figura 19) que se ha empleado en otros trabajos, porque el estilo siempre existe aunque no siempre se reconoce.

Los términos "apical" y "subapical" para referir la posición del estigma (carácter 11) se emplean aquí en el mismo sentido que otros autores (Trelease, 1922; Trelease y Yuncker, 1950; Yuncker, 1950, 1974; Standley y
Steyermark, 1952; Steyermark, 1984; Valdebenito et al., 1992), y no se relacionan ni con el desarrollo, ni con la morfología carpelar.

En el presente trabajo no se emplean los términos "anterior" (figura 21), "central", "subcentral" (figura 23) y "lateral", para referir la posición del estigma en el fruto (Dahlstedt, 1900; Yuncker, 1974, Valdebenito et al., 1992), ya que éstos se consideran redundantes y no homólogos con los términos "apical" y "subapical".

La protuberancia estilar (carácter 12) es una característica que se relaciona con los subgéneros Rhyncophorum y Sphaerocarpidium. En el presente trabajo, el término "pico" no se utiliza para describir la protuberancia estilar, ya que este término se usa indistintamente por otros autores, para designar la protuberancia estilar o para los estilos con forma cilíndrica o cónica (Hill, 1907; Yuncker, 1950, 1974; Burger, 1971; Boufford, 1982; Steyermark, 1984).

La inclinación de la protuberancia estilar (Yuncker, 1950; Steyermark, 1984) no se contempla en el carácter 13, por lo cual el término "recurvado" no es equivalente con la forma de gancho de la punta de la protuberancia estilar. En P. collocata, P. magnoliaefolia y P. obtusifolia se observaron diferentes ángulos de inclinación de la protuberancia estilar de los frutos de una misma especie, lo cual confirma que estos ángulos no tienen un valor taxonómico.

Los caracteres y los estados de carácter establecidos en este trabajo representan la va riación del fruto en las especies de Peperomia examinadas aquí. La estructura del fruto se puede utilizar para apoyar la identificación de las especies de Peperomia. Se reconoce que hace falta una búsqueda de más caracteres y estados de carácter en otros subgéneros y especies.

Los caracteres del fruto que aquí se señalan apoyan la segregación de las especies de Peperomia en los subgéneros Micropiper y Sphaerocapidium de Dahlstedt (1900). Tildenia es el subgénero que presenta la mayor variación en la estructura del fruto.

\section{Literatura citada}

Barrios M.A., Cota H. y Medina-Cota M. 1987. Una especie nueva de Peperomia (Piperaceae) del Valle de México. Phytologia 62:54-57.

Boufford D.E. 1982. Notes on Peperomia (Piperaceae) in the Southeastern United States. Journal of the Arnold Arboretum 63:317-325.

Brown W.H. 1908. The nature of the embryo sac of Peperomia. Botanical Gazette 46:445-460.

Burger W.C. 1971. Flora Costaricensis. Piperaceae. Fieldiana Botany 35:5-217.

Calderón G. y Rzedowski J. Eds. 2001. Flora Fanerogámica del Valle de México. 2a. ed., Instituto de Ecología, A.C. y Comisión Nacional para el Conocimiento y Uso de la Biodiversidad, Pátzcuaro. 
Callejas R. y Betancur J. 1997. Especies nuevas de Piperaceae de los Andes al sur de Colombia. Novon 7:17-24.

Campbell D.H. 1899. Die Entwicklung des Embryo-sackes von Peperomia pellucida Kunth. Berichte der Deutschen Botanischen Gesellschaft 17:452-456.

Candolle A.De. 1869. Prodromus Systematis Naturalis Regni Vegetabilis. 16. Urticaceas, Piperaceas, etc. Victoris Masson et Filii, París.

Corner E.J.H. 1976. The Seeds of Dicotyledons. Vol. 1. Cambridge University Press, Cambridge.

Cronquist A. 1981. An Integrated System of Classification of Flowering Plants. Columbia University Press, Nueva York.

Dahlstedt H. 1900. Studien uber Süd- und CentralAmerikanischen Peperomien. Kongliga Svenska VetenskapsAkademiens Handlingar 33:1-128.

Dodson C.H. y Gentry A.H. 1978. Flora of the Rio Palenque Science Center. Selbyana 4:478-500.

Espinosa-Osornio G. y Engleman M.E. 1998. Breve Recopilación de Anatomía de Semillas. Colegio de Postgraduados, Texcoco.

Görts-Van Rijn A.R.A. 1988. Peperomia gracieana (Piperaceae), a new species from French Guiana. Brittonia 50:56-58.

Gvaladze G.E. y Akhalkatsi M. 1990. Is the Polygonum type embryo sac primitive? Phytomorphology 40:331-337.

Gvaladze G.E. y Akhalkatsi M. 1998. Double fertilization in Peperomia pellucida. Phytomorphology 48:405-409.

Hill A.W. 1906. The morphology and seedling structure of the geophilous species of Peperomia, together with some views on the origin of monocotyledons. Annals of Botany 20:395-427.

Hill A.W. 1907. A revision of the geophilous species of Peperomia with some additional notes on their morphology and seedling structure. Annals of Botany 21:139-160.

Johnson D.S. 1900. On the endosperm and embryo of Peperomia pellucida. Botanical Gazette 30:1-11.

Johnson D.S. 1902. On the development of certain Piperaceae. Botanical Gazatte 34:321-340.

Johnson D.S. 1914. Studies of the development of the Piperaceae. II. The structure and seed-development of Peperomia hispidu la. American Journal of Botany 1:323-339, 357-397.

Jones S.B. 1988. Sistemática Vegetal. McGraw-Hill, México, D.F. Maheshwari P. y Kapil R.N. 1966. Some Indian contributions to the embryology of angiosperms. Phytomorphology 16:239291.

McKendrick M. 1992. Peperomias. Garden 117:352-356.

Miquel F.A.G. 1843. Sistema Piperacearum. H.A. Kramers, Rotterdam.

Murty Y.S. 1952. Placentation in Peperomia. Phytomorphology 2:132-134.

Nikiticheva Z.I. 1981. Embryological features of some Piperales. Acta Societatis Botanicorum Poloniae 50:329-332.

Nyffeler R. y Rowley G.D. 2002. Genus Peperomia. En: Eggli U. Ed. Illustrated Handbook of Succulent Plants - Dicotyledons -. Springer Verlag, Heidelberg.

Pino G., Klopfenstein O. y Cieza N. 2003. Three new taxa of
Peperomia from northern Peru. Cactus and Succulent Journal 75:27-36.

Rauh W. y Barthtlott W. 1975. Two new species of succulent peperomias from South America. Cactus and Succulent Journal 47:198-208.

Standley P.C. y Steyermark J.A. 1952. Flora of Guatemala. Fieldiana Botany Vol. 4. Part 3. Chicago Natural History Museum, Chicago.

Steyermark J.A. 1984. Flora de Venezuela - Piperaceae. Ediciones Fundación Educación Ambiental, Instituto Nacional de Parques, Dirección de Investigaciones Biológicas, Caracas.

Takhtajan A. 1988. Anatomia Seminum Comparativa. Tomus 2. Nauka, Leningrado.

Thorne R.F. 1992. Classification and geography of the flowering plants. Botanical Review 58:225-348.

Trelease W. 1922. The peltate peperomias of North America. Botanical Gazettte 73:133-147.

Trelease W. y Yuncker T.G. 1950. The Piperaceae of Northern South America. Vol. 2. University of Illinois Press, Urbana.

Tucker S.C. 1980. Inflorescence and flower development in the Piperaceae: I. Peperomia. American Journal of Botany 67:686702.

Tucker S.C., Douglas A.W. y Han-Xing L. 1993. Utility of ontogenetic and conventional characters in determining phylogenetic relationships of Saururaceae and Piperaceae (Piperales). Systematic Botany 18:614-641.

Valdebenito H. 1988. Seed morphology and relationships of four endemic species of Peperomia (Piperaceae) of the Juan Fernández islands, Chile. Ohio Journal of Sciences 88:13.

Valdebenito H., Stuessy T.F. y Crawford D.J. 1992. Evolution of Peperomia (Piperaceae) in the Juan Fernández Islands, Chile. Plant Systematics and Evolution 182:107-119.

Wanke S., Samain M.S., Vanderschaeve L., Mathieu G., Goetghebeur P., Neinhuis C. 2006. Phylogeny of the genus Peperomia (Piperaceae) inferred from the $\mathrm{trnK} / \mathrm{matK}$ region (cpDNA). Plant Biology 8:93-102.

Yuncker T.G. 1936. The Piperaceae of Argentina, Bolivia and Chile. Field Museum of Natural History Botanical Series 13:8303.

Yuncker T.G. 1950. Flora of Panama. Piperaceae. Annals of the Missouri Botanical Garden 37:1-120.

Yuncker T.G. 1956. South American Piperaceae: new species and nomenclatural notes on two previously published taxa. American Journal of Botany 43:161-168.

Yuncker T.G. 1958. The Piperaceae - A family profile. Brittonia 10:1-7.

Yuncker T.G. 1961. New taxa of Peruvian Piperaceae. Brittonia 13:58-63.

Yuncker T.G. 1966. New species of Piper and Peperomia (Piperaceae) from Peru. Annals of the Missouri Botanical Garden 53:381-384.

Yuncker T.G. 1974. The Piperaceae of Brazil. 3. Peperomia. Hoehnea 4:71-413. 